\title{
Xeroradiography in assessment of the rheumatoid han
}

\author{
C. R. LOVELL, M. BROCK, M. I. V. JAYSON, AND H. BADDELEY \\ From the Departments of Medicine and Radiodiagnosis, University of Bristol
}

SUMMARY Comparable conventional $x$-rays and xeroradiographs were obtained of the hands of 22 patients with rheumatoid arthritis. Each metacarpophalangeal and proximal interphalangeal joirut was scored for juxta-articular osteoporosis, erosions, loss of joint space, soft tissue thickening, joint deformity, and osteophytes on a 0-3 scale. For 10 hands the films were reported again after $\overline{\$}$ months, and each technique was reproducible. Comparison between the 2 radiographic technique्s showed that overall they gave similar results, although osteoporosis was reported more frequent on conventional $x$-rays, and loss of joint space and synovial thickening on xeroradiographs.

Radiology plays an essential part in the diagnosis and management of rheumatoid disease. Until recently the only practical means of recording the image produced after attenuation of the $x$-ray beam by the body tissues has been photographic emulsion. Either the direct effect of the $x$-rays on the emulsion can be used (nonscreen film), or the indirect effect of the $x$-rays producing emission of light from sensitive phosphors (screen film).

Systems are now available for recording $x$-ray images using the ionizing effect of $x$-radiation falling on a charged plate. The best known of these is xeroradiography, a derivation of the xerox process used for photocopying. A charged semiconducting plate is exposed to $x$-radiation and is discharged by the incident $x$-ray photons; the degree of discharge being proportional to the amount of radiation falling on any single area. A charge image is formed which is rendered visible by spraying the plate with oppositely charged particles; the final image is then produced on paper.

There are important differences between the image produced by conventional and xeroradiography. Xeroradiographs have a much wider exposure latitide enabling bone and soft tissue detail to be shown on a single film. Another important feature is the edge enhancement characteristic of xeroradiographs, resulting in clear definition of zones of differing density, even where the difference is small. The radiation exposure in xeroradiographs of the extremities is less than that for nonscreen film radiography.

We have compared the two techniques in the

Accepted for publication February 24, 1977

Correspondence to Dr. C. R. Lovell, Department of Rheumatology, Bristol Royal Infirmary, Bristol BS2 8HW assessment of the rheumatoid hand to ascertan whether the properties of the xeroradiograph confer any advantage over conventional radiography of the hand.

\section{Materials and methods}

Studies were performed on 26 patients ( 20 females 6 males) with classical or definite rheumatod arthritis (Ropes et al., 1959) who had clinical i⿺辶. volvement of the hands such as synovial swelling and joint deformity. The length of history ranged fro 4 months to over 10 years. With each patient 3 informed consent, we took comparable convention $x$-rays and xeroradiographs of the hands in a dors palmar projection. The films were coded and read on separate occasions by two rheumatologis working together. Each metacarpophalangeal ang proximal interphalangeal joint was scored separatefy with respect to each of the following recognized radiological features of rheumatoid disease: ( juxta-articular osteoporosis, (2) erosions, (3) loss 8 joint space, (4) soft tissue thickening, (5) joint deformity, (6) osteophytes. We scored each feature using the following grades: $0=$ normal, $1=$ doubtfat or minimal change, $2=$ definite change, $3=$ gross abnormality. The maximum possible score was 36 for both hands.

To test the reproducibility of the scoring syste 10 xeroradiographs and 10 conventional $x$-rays wexe each read twice with an interval of 3 months between readings. For each joint and for each feature the number of grades of difference in reporting the sam film on the two separate occasions was noted. We then compared the scores obtained for each feature in each joint in the initial assessments of the 
conventional $x$-rays and xeroradiographs and identified those joints in which the two techniques scored differently and those in which they were the same. Statistical comparisons were drawn for each feature using the sign test, a nonparametric test for paired differences.

\section{Results}

The comparisons between the original and repeat scores for the 10 pairs of conventional $x$-rays and xeroradiographs are shown in Tables 1 and 2 . In approximately two-thirds of the joints repeat examinations of both conventional and xeroradiographs produced the same scores as on the first occasion. Differences were usually of one grade, occasionally two grades, and very rarely three grades. Therefore, it seems that the repeated assessment of the same $x$-ray gives reasonably comparable restults.

Comparisons of the conventional $x$-ray and xeroradiograph scores are given in Table 3 . Joint deformity and osteophytes gave similar scores. With respect to erosion there were many subjects in whom either method scored higher, but overall neither method was more likely to indicate their presence.
However, osteoporosis was significantly more commonly reported on conventional $x$-rays, and loss of joint space and soft tissue thickening was significantly more commonly reported on xeroradiographs.

Fig. 1 shows comparable conventional $x$-rays and
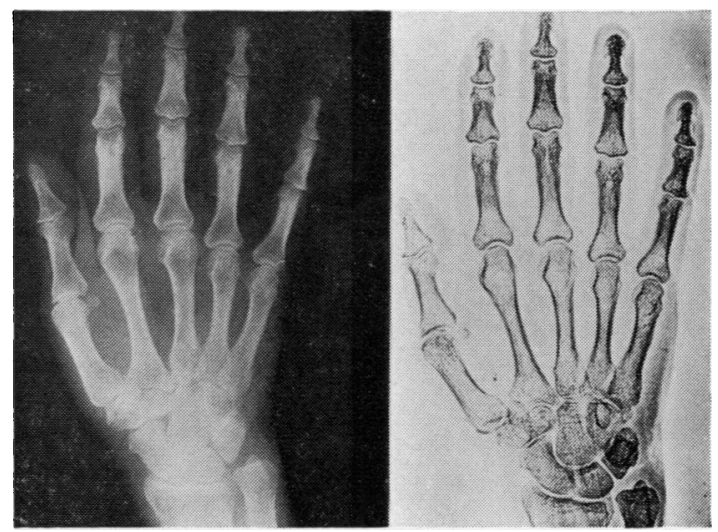

Fig. 1 Comparable conventional $\mathrm{x}-$ rays and xeroradiographs of the rheumatoid hand.

Table 1 Conventional x-rays: comparison of original/repeat scores on 10 pairs of hands (MCP and PIP joints)

\begin{tabular}{lccrrrr}
\hline & Erosions & Osteoporosis & Loss of joint space & Soft tissue thickening & Deformity & Osteophytes \\
\hline Same score & 133 & 153 & 37 & 150 & 148 & 181 \\
\pm 1 & 63 & 10 & 44 & 49 & 189 \\
\pm 2 & 4 & 0 & 2 & 3 & 0 & 0 \\
\pm 3 & 0 & & 0 & 0 & 0 \\
\hline
\end{tabular}

Table 2 Xeroradiographs: comparison of original/repeat scores on 10 pairs of hands (MCP and PIP joints)

\begin{tabular}{lccrrrr}
\hline & Erosions & Osteoporosis & Loss of joint space & Soft tissue thickening & Deformity & Osteophytes \\
\hline Same score & 136 & 138 & 55 & 155 & 158 & 188 \\
\pm 1 & 59 & 7 & 41 & 41 & 10 & 18 \\
\pm 2 & 5 & 0 & 0 & 0 & 2 & 0 \\
\pm 3 & 0 & 0 & 0 & 0 \\
\hline
\end{tabular}

Table 3 Comparison of xeroradiograph and conventional x-ray scores on 26 pairs of hands (MCP and PIP joints)

\begin{tabular}{|c|c|c|c|c|c|c|}
\hline & Erosions & Osteoporosis & Joint space & Soft tissue thickening & Deformity & Osteophytes \\
\hline $\begin{array}{l}\text { Xeroradiograph } \\
\text { scores higher }\end{array}$ & $\begin{array}{r}98 \\
321\end{array}$ & $\begin{array}{r}55 \\
238\end{array}$ & 135 & $\begin{array}{l}118 \\
373\end{array}$ & $\begin{array}{r}27 \\
452\end{array}$ & 20 \\
\hline $\begin{array}{l}\text { Conventional } \\
\text { radiograph } \\
\text { scores higher }\end{array}$ & 101 & 227 & 50 & 29 & 41 & 11 \\
\hline Sign test & NS & $\begin{array}{l}P<0.01 \text { in favour } \\
\text { of conventional } \\
\text { radiographs }\end{array}$ & $\begin{array}{l}P<0.01 \text { in favo.r } \\
\text { of xeroradio- } \\
\text { graphs }\end{array}$ & $\begin{array}{l}P<? \cdot 01 \text { in fav our } \\
\text { of xeroradiographs }\end{array}$ & NS & NS \\
\hline
\end{tabular}

NS = not significant. 

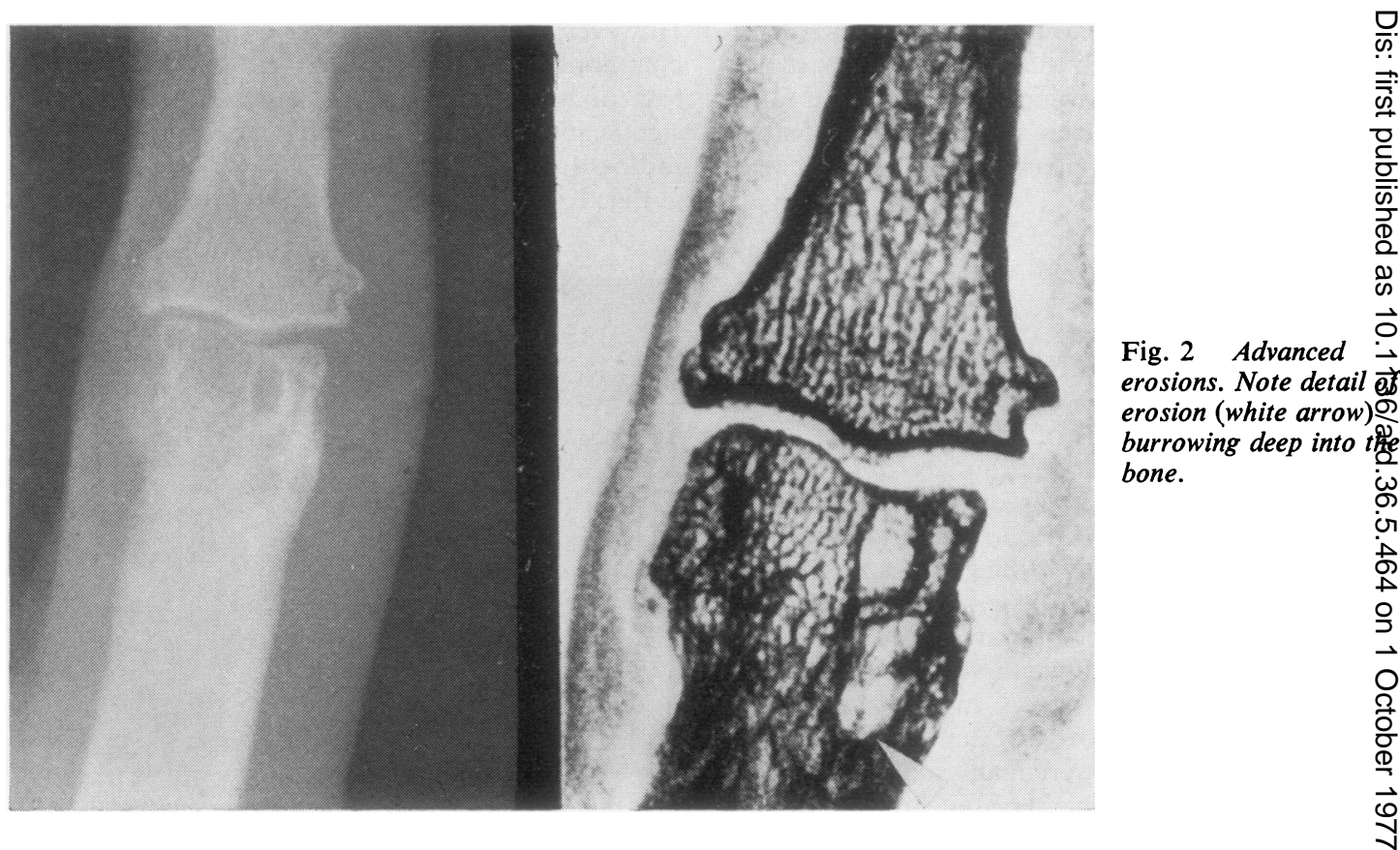

xeroradiographs of the rheumatoid hand. Juxtaarticular osteoporosis is shown by both techniques although it is perhaps more clearly seen in the conventional $x$-ray. Advanced erosions are easily seen on conventional $x$-rays but the xeroradiograph in Fig. 2 shows more clearly the extent of the erosion (arrowed) which is burrowing deep into the bone. Details of soft tissue thickening are also more
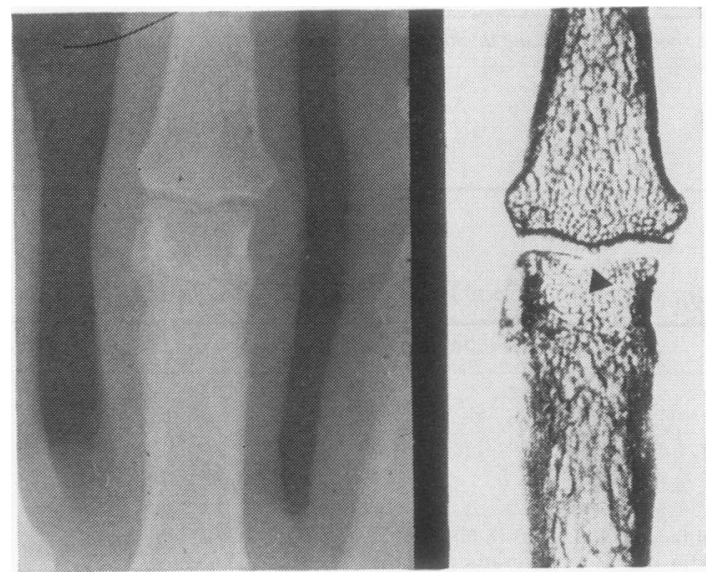

Fig. 3 Erosive changes. Note surface erosion (arrowhead). apparent on the xeroradiograph. In Fig. 3 the xerradiograph not only shows a clear outline of the erosions, but also shows a small surface erosion (arrowed) which is not apparent on the conventional film. The edge enhancement effect can be a advantage in that dense objects create a surroundifig halo of lucency (Fig. 4).

\section{Discussion}

As conventional $x$-rays record the radiograp density of the image projected on to the film plate, and the xeroradiographs record areas of radiggraphic contrast, the two techniques will gi্e different information. Conventional $x$-rays have the advantage of illustrating the absolute density of tissues. This is compatible with osteoporosis beiñg more commonly recognized by this technique. With xeroradiographs the accentuation of areas of contrast makes soft tissue thickening and loss of jolit space more readily identifiable. Although erosions may be made more obvious, sometimes the edge enhancement effect can lead to such loss of detail that the nature of the erosions may be difficult 90 determine. This is why erosions were sometimes recognized more commonly on xeroradiographs and sometimes on the conventional $x$-rays.

It must be stressed that in the absence of patho logical information there are no absolute standaras 


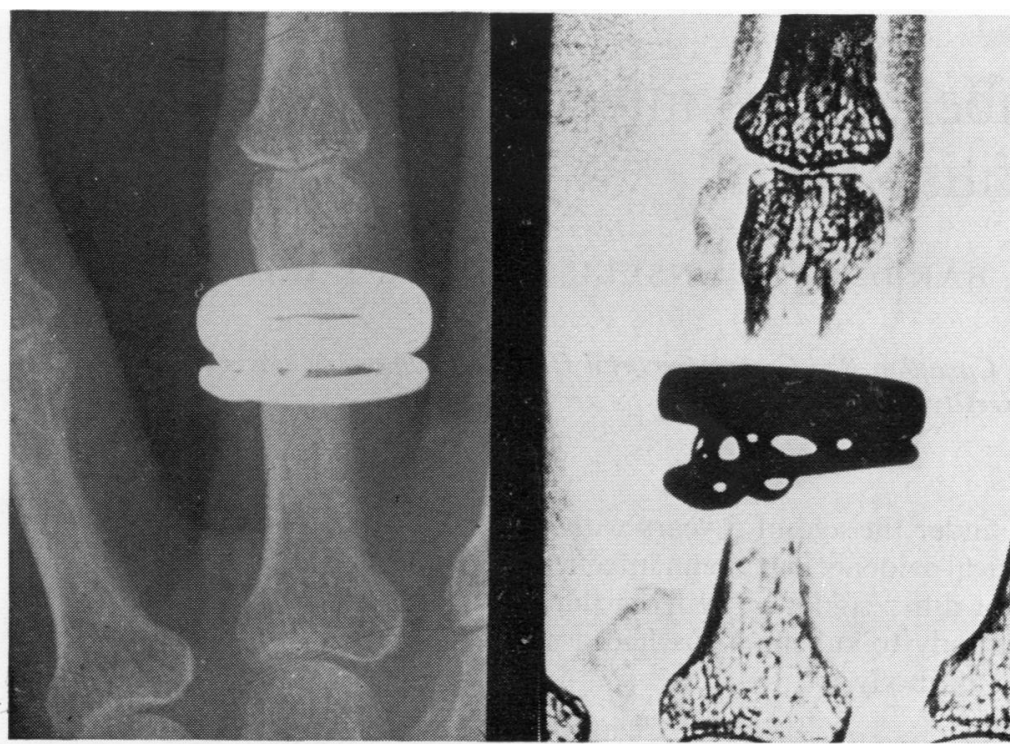

Fig. 4 Edge enhancement effect on xeroradiography.

with which these two types of radiography can be compared. It is not possible to say which gives a 'right' or 'wrong' answer. However, the results of this survey suggest that, on the whole, xeroradiographs are comparable to conventional $x$-rays for assessing rheumatoid hands, although osteoporosis is recognized less readily and loss of joint space and synovial thickening!more readily.
C.R.L. is in receipt of a grant from the Dr. Hadwen Trust, to whom we are most grateful.

\section{Reference}

Ropes, M. W., Bennett, G. A., Cobb, S., Jacox, R., and Jessar, R. A. (1959). Diagnostic criteria for rheumatoid arthritis. 1958 revision. Annals of the Rheumatic Diseases, 18, 49-53. 